\title{
Germanica
}

\section{Emmanuel Béhague, Le théâtre dans le réel. Formes d'un théâtre politique allemand après la réunification (1990-2000)}

Strasbourg, Presses universitaires de Strasbourg, 2006, 382 p.

\section{Anne-Marie Corbin}

\section{OpenEdition}

\section{Journals}

Édition électronique

URL : http://journals.openedition.org/germanica/267

DOI : 10.4000/germanica.267

ISSN : 2107-0784

Éditeur

Université de Lille

Édition imprimée

Date de publication : 1 juin 2007

Pagination : 185-186

ISBN : 2-913857-19-1

ISSN : 0984-2632

\section{Référence électronique}

Anne-Marie Corbin, «Emmanuel Béhague, Le théâtre dans le réel. Formes d'un théâtre politique allemand après la réunification (1990-2000) », Germanica [En ligne], 40 | 2007, mis en ligne le 29 juin 2009, consulté le 06 octobre 2020. URL : http://journals.openedition.org/germanica/267 ; DOI : https:// doi.org/10.4000/germanica.267

Ce document a été généré automatiquement le 6 octobre 2020.

(c) Tous droits réservés 


\title{
Emmanuel Béhague, Le théâtre dans le réel. Formes d'un théâtre politique allemand après la réunification (1990-2000)
}

Strasbourg, Presses universitaires de Strasbourg, 2006, 382 p.

\author{
Anne-Marie Corbin
}

\section{RÉFÉRENCE}

Emmanuel Béhague, Le théâtre dans le réel. Formes d'un théâtre politique allemand après la réunification (1990-2000), Strasbourg, Presses universitaires de Strasbourg, 2006, 382 p.

1 Cet ouvrage est la version remaniée de la thèse de doctorat d'E. Béhague, récompensée par le prix « Adrerus ». Ce travail porte sur les textes dramatiques d'auteurs de théâtre allemands - à l'Ouest comme à l'Est - et leur spécificité depuis l'unification de l'Allemagne en 1990. Il se donne pour objectif d'explorer leur potentiel critique dans le nouveau contexte politique, social et culturel, de proposer une définition adéquate de ce théâtre politique et d'élaborer des «types idéaux » pour répondre à la question de l'ancrage dans la réalité des textes. L'approche choisie est socio-culturelle. La première partie est consacrée à l'écriture dramatique contemporaine dans son cadre institutionnel et théorique, la seconde aux modalités d'un « théâtre de la monstration » qui tend à dépasser le Zeitstück, devenu caduque.

2 Si E. Béhague se tourne également vers le théâtre politique d'Erwin Piscator et sa réinterprétation par Bertolt Brecht, il considère, néanmoins, qu'une véritable césure intervient dans les années 1970 avec le rejet par Heiner Müller de la "pièce didactique ». Dans les années 1990, la dramaturgie constate une forme d'échec du politique (Dea Loher) ou bien celui d'un projet de société (Thomas Oberender). Berlin se retrouve aussi sur la scène, comme une métaphore de l'espace collectif (Simone 
Schneider), une dichotomie fondamentale s'instaurant entre le mouvement historique et la sphère de l'existence individuelle des personnages. L'action peut aussi devenir le reflet du devenir individuel (Dirk Dobbrow). L'interprétation de l'Histoire est surtout présentée pour ses limites (Botho Strauß). Au-delà des apports de la théorie esthétique de Theodor W. Adorno, une nécessaire fin du réalisme s'amorce. Il peut s'agir d'un cas particulier de monologue (Werner Fritsch), d'une remise en cause des catégories dramatiques (Oliver Czeslik) ou d'une mise en scène spécifique (Rainald Goetz).

Les auteurs qui se côtoient ainsi appartiennent à deux systèmes différents, mais ils ont bien des points communs dans leur appréhension du théâtre: lieu de traitement des questions sociales contemporaines, doute jeté sur les modèles explicatifs globaux, remise en cause d'un positionnement critique de l'œuvre d'art par rapport au réel. Ils thématisent la construction ou la déconstruction d'un discours sur le monde. 